\title{
THE DIFFERENCES BETWEEN THE MILITARY FIELD AND THE CIVILIAN FIELDS IN TERMS OF INTERCULTURAL COMPETENCE
}

\author{
Florentina-Lavinia MATEI \\ University of Bucharest, Romania \\ mateilavinia92@yahoo.com
}

\begin{abstract}
This study aimed at investigating significant differences in the level of intercultural competence of students before attending an internship of international mobility by the intermediary of the Erasmus Plus program, depending on their field of study. The three areas of study that imply the students attending the research are: military, exact science and humanities. The research was processed by a questionnaire measuring the level of intercultural competence, the items being structured on the three dimensions of intercultural competence: knowledge, attitudes and abilities. The results indicate that significant differences exist only at the level of the attitude's component, the highest average being registered for the field of exact sciences.
\end{abstract}

KEYWORDS: intercultural competence, civilian fields, military field, Erasmus, students

\section{Introduction}

Obviously, over the past decades, we have witnessed a significant increase in mobility in higher education and the diversification of international cooperation types. Contemporary society emphasizes the development of intercultural interaction among groups belonging to some different cultures.

At the same time, the difference between cultures could be a major problem in the exchange of experience for Romanian students undergoing an internship by the intermediary of an international program such as Erasmus Plus, in which sense an intercultural competence training being needed before coming into contact with a new culture.

For both military and civilian field students who undergo an international mobility stage, intercultural competence can be of major importance, as ownership can positively influence intercultural relations, adapting to the new culture, communicating as best as possible with the members of that culture, but also easily surpassing the cultural shock.

\section{Intercultural Competence - a Key}

\section{Competence}

In the European Framework of Reference Key Competences for Lifelong Learning (2004), one can find, among key competences, the cultural competence, which refers to the importance of creative expression of ideas, experiences and emotions in music, body expression, literature and the fine arts. Based on the statements in the specialty literature, we can say that the starting point of intercultural 
competence is a solid cultural competence, through which one can build an attitudinal openness towards others, this being possible through intercultural learning. Thus, according to Helmut Fennes (1997), this intercultural learning "represents a continuum that most often begins with ethnocentrism and aims at structuring a complex capacity, essential for the efficiency of contacts between cultures. This capacity is called intercultural competence" (apud Nedelcu, 2008, p. 25).

If we analyze intercultural competence, we find from the work Intercultural Competences. Conceptual and Operational Framework (UNESCO, 2013) that it concerns the possession of some relevant knowledge on certain cultures, as well as on the possession of some general knowledge on the types of problems that arise whenever the members of cultures interact differently. Intercultural competence also means having some attitudes that are needed to interact and maintain contact with people from different cultures, as well as skills to understand other cultures.

Intercultural competence is required as a basic skill for any interaction. It is necessary for a person to have social skills to improve sensitivity and understanding of other values, points of view, ways of life and thinking, as well as the self-conscious transfer of their own values and points of view in a clear and appropriate way.

Besides the fact that this intercultural competence develops through attendance to an international mobility, the impact study of the Eramus Plus program, achieved by the National Agency for the Community Program in the Field of Education and Training professional (ANPCDEFP, 2017) team, reveals the fact that the graduates insertion capacity is also improving.

Concluding, this allows the person to better manage relationships in a multicultural space. Thus, besides ethnicity, language, geographical origin, intercultural competence includes in its structure elements of a cognitive, affective and behavioral nature in terms of interaction with groups of various cultures. In this sense, intercultural competence can be useful in interacting with members of groups belonging to some different cultures.

\section{Research Methodology} Research

3.1. Objective and Hypothesis of

This study aims to achieve the following goal:

01. Investigating differences in intercultural competence of students before attending an international mobility program depending on their field of study.

To achieve this goal, the following hypothesis was proposed:

Hypothesis 1 - It is assumed that there is a statistically significant difference in the intercultural competence of students going to an international mobility stage depending on their field of study.

\subsection{Sample of Research}

The study was attended by 130 students $(\mathrm{N}=130), 62$ males and 68 females, aged between 19 and 50 $(\mathrm{m}=22.43, \mathrm{SD}=4.15)$ (Table no. 5) who shall benefit from a mobility internship by the intermediary of the Erasmus Plus program in the academic year 2018-2019. Students were grouped by fields of study, such as (Table no. 1):

Table no. 1

Distribution of students by fields of study

\begin{tabular}{ccc}
\hline $\begin{array}{c}\text { Military } \\
\text { field }\end{array}$ & $\begin{array}{c}\text { Field of } \\
\text { exact } \\
\text { sciences }\end{array}$ & $\begin{array}{c}\text { Field of } \\
\text { humanities }\end{array}$ \\
\hline 45 & 34 & 51 \\
\hline
\end{tabular}

The participants in the research are students from several universities, such as: The Land Forces Academy "Nicolae Bălcescu" of Sibiu, The University of 
Bucharest, The University "Lucian Blaga" of Sibiu, The University "Al. I. Cuza" of Iaşi, the University Ovidius of Constanța, The West University of Timişoara, The University of Medicine and Pharmacy of Cluj, The University Transilvania of Braşov and The National University of Dramatic and Cinematic Art "I. L. Caragiale" Bucharest.

\subsection{Method and Research Tool}

The research was processed by applying a questionnaire measuring the level of intercultural competence of students in the three areas mentioned in the research sample.

The questionnaire used in this study was developed on the basis of the Intercultural Competence Assessment Questionnaire applied by Fantini (2007) in his research entitled Exploring and Assessing Intercultural Competence.

The questionnaire presents 28 items, which correspond to the following dimensions of intercultural competence: knowledge, attitudes and abilities. Items are assessed by using the five-step Lickert scale: this is not the case, to a small extent, somewhat, to a large extent, to a very large extent.

The questionnaire was administered to students to measure the level of intercultural competence before attending the international mobility stage. The questionnaire is to be administered once again at the students' return from the international mobility stage to find out if there are significant differences between the pre-test stage and the post-test stage in terms of intercultural competence level.

The participants in the study expressed their consent of attendance by filing in the questionnaire and were, also, informed that their personal data would be confidential.

To verify the fidelity of the research tool, its internal consistency index was calculated, the following values being obtained:
- 0.78 for the Knowledge Subscale (Table no. 2);

- 0.90 for the Attitudes Subscale (Table no. 3);

- 0.85 for Skills Subscale (Table no. 4).

Table no. 2

The Cronbach Alpha Index for Knowledge Subscale The Cronbach Alpha Index for the Knowledge Subscale

\begin{tabular}{cc}
$\begin{array}{c}\text { Cronbach } \\
\text { Alpha }\end{array}$ & No. of items \\
\hline 0.788 & 6 \\
\hline
\end{tabular}

Table no. 3

The Cronbach Alpha Index for Attitudes Subscale

The Cronbach Alpha Index for Attitudes Subscale

Cronbach Alpha No. of items $0.900 \quad 12$

Table no. 4

The Cronbach Alpha Index

The Cronbach Alpha Index for Skills Subscale

\begin{tabular}{cc}
\hline Cronbach Alpha & No. of items \\
\hline 0.857 & 10 \\
\hline
\end{tabular}

The Cronbach Alpha index registers a good value for each instrument subscale, which means that the items correlate strongly with the scale for the sample of this research.

\section{Results}

The study is longitudinal and presents the pre-test differences regarding the level of intercultural competence for Romanian students in military, exact sciences and humanities fields, attending an international mobility internship.

For the statistical analysis of the study data, a non-parametric test, the Kruskal Wallis test, was applied. 
In Table no. 4, we can notice the descriptive statistics of the values of the research variables. Thus, for the knowledge variable, the average is 21.12 , the minimum value is 14 and the maximum value -30 . The attitudes variable has the average of values of 51.96 , the minimum value is 35 and the maximum one is 60 , while the average of the values of the skills variable is 41.23 , the minimum value is 27 , and the maximum value for this last variable is 50 .

Table no. 5

\begin{tabular}{llllll}
\multicolumn{5}{c}{ Descriptive statistics of data } \\
\hline & $\mathrm{N}$ & Average deviation & Minimum Maximum \\
\hline Knowledge & 130 & 21.1231 & 3.70212 & 14.00 & 30.00 \\
Attitudes & 130 & 51.9615 & 6.46686 & 35.00 & 60.00 \\
Skills & 130 & 41.2308 & 5.97610 & 27.00 & 50.00 \\
\hline
\end{tabular}

In order to achieve the objective of the research, Hypothesis 1 was tested, according to which there is a statistically significant difference in the intercultural competence of students going to an international mobility stage depending on their field of study, being achieved by the application of the Kruskal Wallis Test (Table no. 6).

Table no. 6

\begin{tabular}{|c|c|c|c|}
\hline \multirow{2}{*}{\multicolumn{4}{|c|}{$\begin{array}{c}\text { Kruskal Wallis }{ }^{a, b} \text { Test } \\
\text { The Kruskal Wallia }{ }^{a, b} \text { Test }\end{array}$}} \\
\hline & & & \\
\hline & Knowledge & Attitudes & Skills \\
\hline Chi-Square & 2.651 & 10.568 & 1.099 \\
\hline $\mathrm{df}$ & 2 & 2 & 2 \\
\hline p. & .266 & .005 & .577 \\
\hline
\end{tabular}

a. The Kruskal Wallis Test

b. VI: Field

In Table no. 6, one can notice the fact that the hypothesis 1 is not supported by the statistical data $(\chi 2$ (2) knowledge $=2.65$, $\mathrm{p}=0.266, \mathrm{p}>0.05 ; \chi 2$ (2) attitudes $=10.56$, $\mathrm{p}=0.005 ;<0.05 ; \chi^{2}(2)$ skills $=1.09$, $\mathrm{p}=0.577, \mathrm{p}>0.05$, and, in Table no. 7 , the average of the ranges of the 3 groups organized according to the field of study of the participants are: $\mathrm{m}_{1}=58.23, \mathrm{~m}_{2}=68.03$, $\mathrm{m}_{3}=70.23$, for the knowledge variable, $\mathrm{m}_{4}=53.22, \mathrm{~m}_{5}=80.97$ and $\mathrm{m}_{6}=66.02$ for attitudes variable and $\mathrm{m}_{7}=65.56$, $\left.\mathrm{m}_{8}=70.71, \mathrm{~m}_{9}=61.98\right)$.
Although the significance threshold for the test that verifies the existence of some differences in the attitudes of students going to an internship of international mobility depending on the field of study of the participants (military, exact sciences, humanities) is smaller than 0.05 , that is the hypothesis is confirmed, the thresholds of the significance tests that check the existence of some differences regarding the knowledge and skills of the students that shall depart in an internship of international mobility depending on the participants' field of study, are greater than 0,05 , that is the hypothesis is ruled out. Consequently, as a whole, hypothesis $\mathbf{1}$ is not supported by statistical data, since the conditions for two of the dimensions of the intercultural competence variable (knowledge and skills) are not met, the hypothesis being partially confirmed.

Moreover, if we look at Table no. 7 which includes descriptive statistics of the values of knowledge, attitudes and skills variables, grouped by the field of study ( 1 - military field, 2 - exact sciences field, 3 - humanities field), we shall see that the averages of the ranges of the variables differ significantly from each other only at the level of the attitudes. The averages of the variable attitudes ranges are higher for participants in the field of exact sciences.

Table no. 7

Ranges of the values of the intercultural competencce research variables and

\begin{tabular}{cccc} 
& & & the field of study \\
\hline \multirow{4}{*}{ Knowledge } & Field & $\mathrm{N}$ & Average of ranges \\
& 1 & 45 & 58.23 \\
& 2 & 34 & 68.03 \\
& Total & 130 & 70.23 \\
Attitudes & 1 & 45 & \\
& 2 & 34 & 53.22 \\
& 3 & 51 & 80.97 \\
& Total & 130 & 66.02 \\
& 1 & 45 & \\
Skills & 2 & 34 & 65.56 \\
& 3 & 51 & 70.71 \\
& Total & 130 & 61.98 \\
\hline
\end{tabular}




\section{Conclusions}

The study demonstrates that there are statistically significant differences between the three fields of study only as regards the attitudes component of intercultural competence, which is higher in the field of exact sciences.

As to the averages of the knowledge and skills variables, the results indicate that there are no significant differences between the three fields of study, the highest average for the knowledge variable being recorded for the field of humanities, and for the skills variable, the field of exact sciences records a high average as compared to the other fields.

\section{REFERENCES}

Agenţia Naţională pentru Programe Comunitare în Domeniul Educaţiei şi Formării

Profesionale (ANPCDEFP). (2017). Erasmus+. Ghid de implementare pentru Instituțiile de Invățământ Superior. Versiunea 1,0, available at: https://www.erasmusplus.ro/ library/Superior/2016/KA1/GhidKA103-RO\%20v1.0.pdf, accessed on 10 July 2019.

European Commission. (2004). Key competences for lifelong learning. A European Reference Framework. Directorate General for Education and Culture, available at: https://eur-lex.europa.eu/legal-content/EN/TXT/PDF/?uri=CELEX:52018SC0014\&from=EN, accessed on 01 July 2019.

Fantini, A. (2007). Exploring and assessing intercultural competence. Center for Social Development. Washington University in St. Louis, available at: https://openscholarship.wustl. edu/cgi/viewcontent.cgi? article $=1815 \&$ context $=$ csd research, accessed on 01 July 2019.

Nedelcu, A. (2008). Fundamentele educației interculturale. Diversitate, minorităţi, echitate. Iaşi: Editura Polirom.

United Nations Educational, Scientific and Cultural Organization (UNESCO). (2013). Intercultural Competences. Conceptual and Operational Framework, available at: https://unesdoc.unesco.org/ark:/48223/pf0000219768, accessed on 01 July 2019. 